\title{
CONOCER "CON" LA NATURALEZA. REFLEXIONES (PANDÉMICAS) PARA UNA POSIBLE PEDAGOGÍA MÁS ALLÁ DE LO HUMANO
}

Learning with Nature. (Pandemic) Reflections for a Possible Pedagogy Beyond the Human

CARLO ROSA

UNIVERSIDAD NACIONAL AUTÓNOMA DE MÉXICO (MÉXICO)

CARLOROSA79@GMAIL.COM

ORCID: 0000-0003-3583-4104

DOI: https://doi.org/ 10.5565/rev/mitologias.827 vol. 25 | enero 2022 | 91-106

Recibido: 28/09/2021 | Aceptado: 09/12/2021

Resumen:

La actual crisis sanitaria nos muestra que la domesticación a gran escala de los hábitats naturales, provocando el empobrecimiento de la biodiversidad del planeta, facilita la propagación de virus, como el SARS-CoV-2 (Enciso, 2020: s/p). Esto nos obliga a repensar la relación entre naturaleza y cultura a la luz de la crisis ecológica de nuestro tiempo. Poniendo en relación la perspectiva ecológica de Gregory Bateson, la investigación biosemiótica de Eduardo Kohn y el perspectivismo de Eduardo Viveiros de Castro, realizo una interpretación de las ecocosmologías indígenas para esbozar una propuesta preliminar de pedagogía más allá de lo humano, que pueda alimentar el debate sobre la relación entre cultura y naturaleza en el marco de la educación ambiental y sustentable. 


\section{Palabras clave:}

Ecocosmologías indígenas, interculturalidad, pedagogía ambiental, diálogo de saberes, posthumanismo

\section{Abstract:}

The current health crisis shows us that the large-scale domestication of natural habitats, causing the impoverishment of the planet's biodiversity, facilitates the spread of viruses, such as SARS-CoV-2. This forces us to rethink the relationship between nature and culture considering the ecological crisis of our time. Putting in relation the ecological perspective of Gregory Bateson, the biosemiotic research of Eduardo Kohn and the perspectivism of Eduardo Viveiros de Castro, I make an interpretation of indigenous ecocosmologies to outline a preliminary proposal of pedagogy beyond the human, which can promote the debate on the relationship between culture and nature in the framework of environmental and sustainable education.

\section{Keywords:}

Indigenous eco-cosmologies, Interculturality, Environmental Education, Dialogue of Knowledge, Posthumanism 


\section{Re-encuentros}

La hominización, nos recuerda Morin (1973), requiere un enfoque biológico y humanístico a la vez. Dada la naturaleza biofísica y psico-socio-cultural del hombre, su semejanza con todos los demás sistemas vivos, en las estructuras más fundamentales (Bateson, 2006; 2011; Kohn, 2021), es tan asombrosa que hasta nos puede parecer escalofriante y vertiginoso el evolucionismo. Sin embargo, es esta ciencia que, particularmente a través de algunos de sus intérpretes (Bateson, 2006; 2011; Deacon, 1997; 2011, Kohn, 2021, entre otros), nos demuestra la aparición de la cultura humana como una emergencia co-evolutiva; así como nuestra provisionalidad ante el devenir de una ecología de seres.

Pensar al ser humano y la cultura en estos términos, y no como la divina concesión de un espíritu trascendente o de una naturaleza magnánima, es lo que nos impide aceptar la separación entre cultura y naturaleza como principio y justificación del dominio del hombre sobre los demás sistemas biológicos; empujándonos al humilde ejercicio de "quitarnos" el protagonismo de la escena evolutiva y romper la ilusión del control.

En efecto, si la cultura emerge y es consustancial de un contexto semiótico que excede lo humano (Kohn, 2021), su atribución exclusiva al hombre no se puede considerar como un "hecho natural", sino una operación arbitraria. Este excepcionalismo (Haraway, 2008) proviene de pensar la cultura como sinónimo de referencia simbólica, la cual, hasta donde sabemos, es una habilidad solamente humana. Sin embargo, también la referencia simbólica "[...] como toda semiosis, es en últimas dependiente de los procesos materiales, energéticos y autoorganizacionales más fundamentales de los que emerge" (Kohn, 2021: 78); depende, por tanto, de los otros tipos de signos y representaciones producidos por todos los demás sistemas vivos, en cuanto seres ontológicamente semióticos (Hornborg, 2001).

La moderna y desencantada sociedad occidental, sugiere Bateson (2006), parece haberse alejado casi irremediablemente de dicha idea de "pertenencia" presente en la visión del "todo", de la "unidad sagrada", como fundamento de las antiguas religiones teístas, así como de los mitos de las contemporáneas sociedades animistas (Bateson y Bateson, 2013). A la vez, parece haber doblado intencionalmente la teoría evolucionista a los intereses especie-específicos implícitos en un ideal de progreso basado en la primacía del hombre sobre las otras especies, dominadas como recursos.

La visión de la cultura como privilegio de lo humano, o, para ser más precisos, de un específico ideal humano (el occidental), ha sido explotada, a la par de la dominación de la naturaleza, como justificación para la clasificación colonial de la humanidad: lo natural como ecosistema de lo primitivo, lo cultural como ecosistema de lo civilizado; polos opuestos de la línea recta que Occidente ha trazado en su camino unilineal, imponiéndose a todas las "demás" culturas colonizadas. Durante los siglos más "resplandecientes" de la moderna civilización occidental, la emancipación ha significado un tentativo de salida del estado de naturaleza, no solo en el sentido de una progresiva y sistemática liberación de los instintos animales, sino sobre todo como alejamiento de la naturaleza como hábitat y como babitus cognitivo. En esta perspectiva, el progreso occidental ha coincidido con una continua desviación y control del "mundo natural", visto ahora como ecosistema físico (naturaleza), y ecosistema sub-cultural (aquello de los naturales o primitivos). Con base en esta lógica, muchos ecocidios y epistemicidios (de Sousa Santos, 2010) se han cometido en nombre de "exportar" la modernización occidental a otras latitudes culturales, consideradas como la tabula rasa de la civilización. Junto a esto, la acelerada industrialización del siglo XX ha contribuido al incremento de aquellos procesos que han sido causa de los graves problemas ecológicos que hoy están bajo los ojos de todos, y de los cuales la pandemia actual es, probablemente, una de las manifestaciones más paradigmáticas. 
Algo que nos está enseñando la presente crisis sanitaria global causada por el covid-19 es la arbitrariedad con la que se han utilizado los conceptos de cultura y naturaleza para justificar y seguir sosteniendo esta precisa idea de desarrollo, que ahora demuestra, como un destino inevitable, su insostenibilidad (Latour, 2019). La pandemia ha hecho evidente que el problema ecológico es de todos, pero que no todos lo padecemos de la misma forma; no todos los países lo podrán enfrentar con las mismas "armas" tecnológicas, así como políticas y educativas. También, ha hecho patente que la responsabilidad colectiva ante el inminente colapso ecosistémico (Cortes, 2020: s/p) no puede ser distribuida equitativamente, dado que algunos "proyectos civilizatorios" son evidentemente más responsables que otros. La pandemia está señalando, además, que la agenda política global necesita renovar sus ideas, apuestas y aspiraciones, a la luz de un naciente sujeto cosmopolítico (Stengers, 2014), Gaia, que trasciende el anthropos como campo único y privilegiado de atribución de derechos (Danowsky y Viveiros de Castro, 2017; Latour, 2019).

En esta perspectiva, el encuentro entre ecología e interculturalidad que aquí se propone, y que se puede enmarcar en el diálogo entre el Pensamiento Ambiental Latinoamericano (Galano, 2005; Leff, 2012), la antropología ecológica (Rappaport, 1971), el asíllamado giro ontológico (Ruiz Serna y del Cairo, 2016), el giro ambiental en las humanidades (Hamilton, Gemenne y Bonneuil, 2015), la educación ambiental e intercultural, resulta pertinente para aproximarnos a los problemas ecológicos y epistémicos actuales en una perspectiva que acerca, de forma inter- y transdisciplinaria, lo biológico a lo cultural; intentando trabajar en el intersticio de la línea ilusoria que separa la naturaleza de la cultura.

En este marco se puede colocar el enfoque biocultural, que surge de la idea de no separar el estudio y la conservación de la biodiversidad del estudio y la conservación de las culturas. Esto, tal como señalan Toledo y Barrera-Bassols, por una razón sencilla: las "[...] áreas del mundo donde confluyen los procesos de diversificación biológica, lingüística y agrícola, se encuentran habitadas por sociedades tradicionales, es decir por grupos humanos de carácter rural que no han sido transformados por los fenómenos de modernización agraria" (2008: 40-41). Estas sociedades, mostrando otros tipos de "domesticación" del hábitat, revelan que la diversidad biológica se sostiene en una articulación compleja con el ethos y el estilo de vida: conocimientos, sistemas cognitivos y pedagógicos (corpus); creencias y cosmovisiones (kosmos); prácticas y manejos de los "recursos" naturales (praxis) funcionales al mantenimiento de dicha diversidad. En este marco, el debate sobre el "destino ecológico" del planeta debería plantearse a la luz de un diálogo intercultural con aquellas "ecocosmologías tradicionales" (Hornborg, 2001) que, históricamente, han demostrado ser capaces de mantener una relación más equilibrada con el ambiente; para entender cuáles son los motivos profundos de ese logro que, por contraste, representa uno de los problemas más críticos de la actual crisis civilizatoria de Occidente: el ambiental. $^{1}$

La crisis ambiental es una crisis de la cosmovisión mecanicista y de la racionalidad instrumental vinculada al proyecto moderno de civilización, que degrada el ambiente y desvalora la diversidad cultural. Representa un problema epistemológico que interpela a lo educativo, implicando la búsqueda de una nueva ética para la sustentabilidad y la adopción de un nuevo paradigma capaz de reconocer la complejidad de las interconexiones entre seres humanos y ambiente (Galano, 2005), frente a un sistema escolar global que sigue siendo prevalentemente reduccionista (Sterling, 2011).

\footnotetext{
${ }^{1}$ En el Manifiesto por la vida, documento que surgió del Simposio sobre Ética y Desarrollo Sustentable, celebrado en Bogotá, Colombia, los días 2-4 de mayo de 2002, se sostiene que la crisis ambiental es una crisis civilizatoria. Consultado en <http://www.pnuma.org/educamb/documentos/Manifiesto.pdf> (10/03/2021).
} 
Leff identifica como "propia" del Pensamiento Ambiental Latinoamericano una concepción de la sustentabilidad que surge de la relación que las sociedades indígenas y campesinas mantienen con su ambiente. En cuanto tal, difiere "[...] de otros sistemas de pensamiento por un concepto epistemológico radical de medio ambiente, y adquiere su identidad a partir de la herencia cultural de sus pueblos y de los potenciales ecológicos de sus territorios" (Leff, 2012: 97). En esta perspectiva, la educación para la sustentabilidad aboga por una pedagogía basada en el diálogo entre saberes, académicos y populares.

Este intercambio, que podríamos definir aquí como inter-eco-cultural, solicita una "provincialización" de la epistemología. Con esta idea me refiero, por un lado, a la necesidad de una relativización crítica de la cultura y del conocimiento occidental (en su articulación científica, social y humanística) como referencia única y universal, para entregarse a una ecología de saberes (de Sousa Santos, 2010) en la cual el conocimiento occidental es puesto en una relación circular - y ya no como juez supremo- con otras formas de saberes-haceres. Por el otro, me refiero a una apertura de la epistemología más allá del humano, es decir, un abrirse a la posibilidad de considerar la naturaleza como agente gnoseológico, social y pedagógico.

En los siguientes apartados intento ahondar en este diálogo, poniendo en relación la perspectiva ecológica de Gregory Bateson, la investigación biosemiótica de Eduardo Kohn y el perspectivismo de Eduardo Viveiros de Castro. Con ello, realizo una interpretación de las ecocosmologías indígenas para esbozar una propuesta preliminar de pedagogía más allá de lo humano, que abone al debate sobre la ambientalización de la educación (Noguera, 2004); como una reconfiguración del espacio educativo en el que las figuras de sujeto y objeto, de naturaleza y cultura, tal como los ha conceptualizado la modernidad, se desdibujan, vislumbrando un escenario pedagógico conformado por protagonistas inéditos.

Lo que me interesa, específicamente, es el aspecto epistémico y pedagógico emergente de las ecocosmologías indígenas: ¿qué significa conocer con la naturaleza? ¿Cuáles relaciones interculturales emergen de este conocimiento? Y, finalmente, ¿qué tipo de pedagogía?

\section{La mente eco-lógica}

La ecología, para Gregory Bateson, debe entenderse como un problema epistemológico y, entonces, mental (2011). La mente, para el científico británico, es un sistema complejo, amplio y flexible que presenta características determinadas capaces de producir, como cualidad emergente, autonomía y autorregulación. Estas características no se encuentran en algunas especies exclusivamente, como los humanos y los animales, ni en partes específicas del cuerpo, como el cerebro, sino en la relación, en varios contextos, de entidades heterogéneas y partes de tales entidades. En este sentido, para Bateson, la mente es un sistema relacional y los límites de tal sistema dependen del punto de observación, más o menos amplio: todas las entidades que exhiben la complejidad descrita pueden considerarse mentes o submentes de un sistema más amplio.

Si el sistema mental no se encuentra exclusivamente en el cerebro o en alguna otra entidad específica, entonces no puede ser confinado por la piel o por una membrana que define el espacio entre un interior y un exterior, por lo que dentro y fuera se vuelven conceptos relacionales, en cuanto dependen del contexto. En este sentido, no sería del todo correcto afirmar que el hombre está dotado de un sistema mental, sino que constituye un sistema mental, en el cual el cerebro es sin duda una parte necesaria y fundamental tanto como los órganos sensoriales, pero no suficiente para definir la mente en su complejidad. Asimismo, este sistema no se agota en las relaciones que células y órganos tejen 
internamente, en la que Bateson (2010) define como una "danza interna", sino que se extiende también en una "danza externa", es decir, estableciendo relaciones con todas las otras entidades que se encuentran "fuera" del sí. En esta perspectiva, la célula, los órganos, los animales, las plantas, los hombres, e inclusive los virus, representan subsistemas que conforman un sistema mental más amplio y complejo, al que se puede nombrar como eco-sistema mental.

El término "eco", por lo tanto, sugiere la idea de que este sistema no es específico de una o varias especies por separado, sino que es, por así decirlo, inter - y trans- especie, en cuanto implica la participación de los así llamados ecosistemas culturales "con" los ecosistemas naturales, pero también "con” aquellas "entidades" que no pueden responder a ningún estímulo externo, como las piedras. Esto significa, en otras palabras, que todo sistema vivo es y conforma un sistema mental, y es tal porque conoce, aprende: asume comportamientos efectivos en un contexto determinado (Maturana y Varela, 2003). Para reconocer esto, sin embargo, tenemos que asumir que todo ser viviente es un sistema semiótico, es decir, capaz de producir e interpretar signos; y que los interpretantes de estos signos contribuyen a constituir, a su vez, otros "sistemas mentales", otros pensamientos que se proyectan en el tiempo y en el espacio (Kohn, 2021; Dennet, 2000), exactamente como lo hace un ecosistema.

Sin embargo, es importante hacer una distinción entre el mundo animado e inanimado, introduciendo dos términos fundamentales para comprender la ecología de la mente: la Creatura y el Pleroma. Los objetos inanimados, pertenecientes al mundo "[...] que los gnósticos y Jung llamaron Pleroma, [que se podría imaginar] más o menos como el mundo de la física y las bolas de billar" (Bateson, 2010: 411; la traducción es mía), no constituyen mentes "en sí mismas", ya que son incapaces de procesar información, es decir, de responder activamente a estímulos y comunicar. Tales entidades pueden volverse parte del sistema mental, el mundo de la Creatura, solo en relación con él. Uno de los ejemplos más claros presentados por Bateson, para demostrar que el sistema mental trasciende el neural, es el del hombre que camina con un bastón (2006): ¿dónde comienza la mente de un hombre que camina con un bastón?, pregunta el científico, ¿`en el mango del bastón o en la piel de su mano? ¿Y dónde termina?, ¿al final del bastón? Esta cadena de preguntas demuestra la imposibilidad de considerar el bastón como un objeto separado del ciego. El bastón forma parte del sistema mental del ciego como un "canal" a través del cual se transmite la información necesaria para identificar la presencia de una mente en un agregado de partes interactuantes. En este sentido, para explicar la caminata del ciego, debemos necesariamente referirnos al contexto, que incluye el bastón y la calle. Por lo tanto, el ciego que camina es "mentalmente inmanente" a su bastón. Según Bateson, características similares a la relación del sistema mental del hombre con el medio ambiente se encuentran también en contextos donde el hombre está ausente; por ejemplo, en organizaciones muy primitivas como las playas o los bosques, que demuestran ser sistemas autocorrectivos.

Lo expuesto muy sintéticamente sobre algunos puntos nodales del pensamiento de Bateson manifiesta la insuficiencia de las dicotomías sobre las cuales se organiza el conocimiento moderno: mente/cuerpo y naturaleza/cultura. El uso de los términos gnósticos de Pleroma y Creatura intenta superar dichas dicotomías, revelando la urgencia de reparar el "desgarro" que han causado. En efecto, aunque la diferencia entre el mundo de la Creatura y del Pleroma sugiere un dualismo basado en la presencia o ausencia de un "sistema mental", nunca refleja una separación rígida, sino, más bien, una complementariedad; escribe el científico: "Las leyes de la física y de la química no son en algún modo irrelevantes para la Creatura [...], sólo que no son suficientes [...]” (Bateson y Bateson, 2013: 35).

\section{¿Qué significa conocer con la naturaleza?}

Ahora bien, a la luz de la revisión del concepto de mente propuesto por Bateson, como un sistema que nos pertenece, pero al que, al mismo tiempo, nosotros pertenecemos ¿qué es el conocimiento? 
También esta habilidad, cimentada en la capacidad cognitiva de producir e interpretar signos, y que suele atribuirse solo al ser humano o, eventualmente, a algunos animales dotados de una "inteligencia acentuada", debe revisarse en el marco de la epistemología propuesta por Bateson: "Me entrego [escribe el científico] a la creencia de que mi conocimiento es una pequeña parte de un conocimiento integral más amplio que entrama a toda la biosfera o creación" (2011: 102). Definiendo los supuestos de su investigación, Bateson aclara qué entiende por epistemología: "[...]cómo nosotros podemos saber alguna cosa. [Donde] en el pronombre nosotros [están] incluidos [...] la estrella de mar, y el bosque de secuoyas, el huevo que se divide y el Senado de Estados Unidos" (Bateson, 2011: 14; cursivas del original). En este sentido, la epistemología no se reduce al estudio filosófico de cómo es posible el conocimiento, sino que constituye una investigación ampliada de aquellos fenómenos que ocurren "[...] en la línea del encuentro y como rama de la historia natural" (Bateson, 2013: 38). Se trata de una especie de meta-ciencia que incluye " [...] la evolución, el pensamiento, la adaptación, la embriología y la genética —la ciencia del espíritu en el sentido más amplio de la palabra_-" (Bateson, 2011: 101); donde la comparación de estos fenómenos, del pensamiento con la evolución, y la epigénesis con ambos, representa su método de investigación.

Uno de los objetivos del trabajo de Bateson es demostrar la unidad necesaria entre pensamiento y evolución; es decir, en otros términos, que la dimensión cultural no está separada de la natural, sino que emerge de ella. Si bien estas dimensiones muestran diferencias, las similitudes las preceden (Kohn, 2021: 90). Bateson define el pensamiento y el aprendizaje humanos con el concepto de "epistemología con la 'e' minúscula" (Bateson y Bateson, 2013: 38), y la evolución, la adaptación, la embriología y la genética, es decir el "pensamiento más amplio" de la Creatura, como "Epistemología con la "E' mayúscula" (Bateson y Bateson, 2013: 41). Aunque a veces con-funde los dos términos, afirmando, por ejemplo, que hizo falta mucho pensamiento para hacer una rosa (2013), el autor es consciente de que, si bien estas dos epistemologías estén ancladas en cimientos comunes, presentan también diferencias fundamentales. La principal es el surgimiento, en el hombre, de un tipo específico de finalidad que llama "propósito consciente", que está ausente en el sistema mental del resto de la Creatura. Este peculiar tipo de conciencia, a la vez que ha permitido inventos científicos, tecnológicos y progresos asombrosos en varios campos del saber y de la cultura humana, ha provocado también problemas nodales.

El "propósito consciente", que puede resumirse muy sintéticamente como la capacidad de alcanzar fines determinados utilizando medios específicos, sugiriendo la presunción de una superioridad de lo humano sobre el resto de la Creatura, provocaría un problema de integración tan grave entre las dos epistemologías (del hombre y de la Creatura), que debería considerarse como el equivalente de una "falla evolutiva"; en cuanto amenaza la existencia de los lazos y las relaciones fundamentales que constituyen la infraestructura evolutiva de todos los seres vivientes. Esto porque el propósito consciente presenta, en sus más extremas consecuencias, el "efecto colateral" de "[...] generar un sentimiento de separación radical [...]” (Kohn, 2021: 59-69) respecto al resto de la Creatura, ${ }^{2}$ provocando el riesgo de un alejamiento abismal del mundo natural y entregándonos a la idea delirante de la posibilidad de una vida humana sin el planeta Tierra; vislumbrada no solamente por cierta narrativa distópica de ciencia ficción, sino también por algunos trans-humanistas (Danowsky y Viveiros de Castro, 2017).

Percibiendo el peligro de este desgarro radical, Bateson madura la convicción de que la lógica que está en los fundamentos del propósito consciente nunca es del todo compatible con el pensamiento de la Creatura. La estructura del propósito consciente se puede identificar, en su dimensión más elemental, en el silogismo categórico: los hombres son mortales/Sócrates es un hombre/Sócrates es mortal; mientras que el pensamiento de la Creatura estaría anclado a otro tipo de tipo de silogismo, que el autor define como silogismo de la hierba: "la hierba perece/los hombres perecen/los hombres son hierba" (Bateson y Bateson, 2013: 45). La diferencia fundamental entre estos dos "esqueletos" es que el silogismo

\footnotetext{
2 Tomo esta idea de Kohn, 2021, el cual sostiene que la referencia simbólica puede generar una separación radical del mundo natural. Considero que referencia simbólica y propósito consciente son hábitos cognitivos complementarios.
} 
aristotélico identifica clases y sujetos de proposiciones y el de la hierba trata de ecuaciones (relaciones) entre predicados. Básicamente, el primero se basa en la lógica atemporal del "si ... entonces" (Sócrates, en cuanto hombre, es mortal), mientras el segundo intenta describir aquellas relaciones de interdependencia y "similitud" que, aunque muy distantes en el tiempo y el espacio, hacen coincidir el hombre con la hierba. Pero ¿qué significa, más precisamente, que el hombre es hierba?

Evidentemente, no significa que podamos cortar a los hombres como lo hacemos con el césped, pero este silogismo tampoco es un simple "embellecimiento poético", sino, más bien, la "descripción" de los lazos fundamentales que permiten la existencia tanto de la hierba como del hombre, capturados en su interdependencia. Por tanto, la posibilidad de que el hombre sea hierba se debe buscar en la "sustancia", que debe entenderse como el "[...] pegamento organizador de este mundo del proceso mental [...]" (Bateson, 1989: 46). Es decir, hombre y hierba, que por razones obvias no pueden ser lo mismo en muchos ámbitos de la existencia, constituyen una "unidad necesaria" dentro del ecosistema mental, por el hecho de que comparten la misma estructura de vínculos básicos. ${ }^{3}$ Los silogismos que describen esta estructura nos permiten, por tanto, reconocer la metáfora, es decir la pauta que conecta que "somos nosotros"; donde con el pronombre "nosotros" entendemos no solamente los seres humanos, sino todos los otros seres vivos y eventos con los cuales compartimos la vida en la Tierra.

En este sentido, Bateson sostiene que si bien los "lógicos por profesión" tienen sobrados motivos para criticar los silogismos de la hierba, como una "afirmación del consecuente", al mismo tiempo argumenta que sería estúpido desecharse de ellos, dado que representan "[...] la sustancia misma de que está hecha la historia natural" (Bateson y Bateson, 2013: 45): "toda la conducta animal, toda anatomía repetida y toda la evolución biológica, cada una de estas varias esferas está eslabonada dentro de sí misma por los silogismos de la hierba, les guste o no les guste a los lógicos” (Bateson y Bateson, 2013: 46). Entender esto es realmente fácil: para obtener silogismos categóricos debemos identificar clases de tal manera que podamos diferenciar sujetos y predicados. "Pero, fuera del lenguaje, no hay clases nombradas, ni relaciones de sujeto y predicado. Por eso los silogismos de la hierba deben ser el modelo dominante para comunicar la interconexión de ideas en todas las esferas preverbales" (Bateson y Bateson, 2013: 46). Parafraseando a Kohn (2021) podríamos decir que los silogismos de la hierba son un ejemplo de cómo los sistemas vivos más allá del hombre producen e interpretan signos, piensan y conocen; donde es esta habilidad que los dota de un punto de vista, de la capacidad de proyectarse hacia el futuro y mostrar cierto grado de intencionalidad. Los dota, en síntesis, de agencia gnoseológica, y, como trataré de demostrar, también social y pedagógica.

\section{Con-conocer co(s)munitario}

Conocer, en el marco de esta mente eco-lógica, no debe entenderse como conocimiento "de" o "sobre" algo, sino "con-alguien". Consiste en un conocer con "otro de sí no-humano", entendido como otro sistema mental, independientemente de su naturaleza: animal, río, planta, virus... o ecosistema, que surge de la interacción de estas u otras entidades.

Lo mencionado implica por lo menos dos cuestiones relevantes. La primera es que, dado que en esta perspectiva la mente trasciende el sistema neural y la piel, entonces también el yo consciente, que tradicionalmente se hace coincidir con una mente localizada en el cerebro, debería repensarse a la luz de las relaciones que el hombre teje con otros sistemas mentales u otros objetos que entran en su circuito (recordemos el ejemplo del hombre que camina con el bastón, descrito anteriormente). La segunda

\footnotetext{
${ }^{3}$ Esto alude a la idea de coevolución, que Bateson ejemplifica hablando de la evolución del caballo y de la hierba, sosteniendo que el caballo no evoluciona en el vacío, sino coevoluciona con la hierba; por esto, su evolución se debe entender junto con la evolución de la hierba (2010: 411-422).
} 
cuestión es que el con-conocer implica reconocer en otros sistemas mentales no-humanos seres dotados de agencia gnoseológica, es decir, capaces de producir e interpretar significados de por sí, y no solamente en presencia de los hombres por su habilidad simbólica. ${ }^{4}$

Reconociendo esta "fluidez" del yo y la agencia gnoseológica en seres no-humanos es que el conocimiento pasa de ser un proceso que se realiza "desde" una entidad activa (hombre) "sobre" una entidad pasiva (naturaleza), como "conocimiento de algo", según la tradicional dicotomía sujeto/objeto, cultura/naturaleza, a una interacción recíproca entre un sujeto humano que conoce con otro "sujeto" no-humano que también conoce (conocimiento "con-alguien"). Quizá, esta idea se entienda mejor retomando las reflexiones de Kohn. Si todo ser viviente es un ser semiótico, los signos que produce, por la naturaleza relacional de la semiosis, siempre están dirigidos a algún "alguien", es decir algún sistema mental humano o no-humano, presente en el espacio actual o proyectado en el futuro; el cual los interpretará y producirá a su vez otros signos, dando vida a una "cadena semiótica viviente" (Kohn, 2021: 47). Esto hace del conocer, es decir de la capacidad de adquirir hábitos de cualquier sistema mental (humano o no-humano), un proceso ontológicamente intersubjetivo.

Subrayo el sustantivo "sujeto" y el pronombre "alguien" para referirme a los otros de sí nohumanos, porque la agencia gnoseológica solicita reconocer en ellos una subjetividad, es decir, propiamente, un punto de vista, un yo, una intencionalidad. No se trata, sin embargo, de la proyección "creacionista" de un espíritu trascendente (el relojero ciego descrito por Paley) o de un homúnculo, sino del reconocimiento de que ahí donde hay semiosis existe una mente y, entonces, un elemento, o una organización de elementos, que puede considerarse como un sujeto capaz de influir en el comportamiento de los demás "sí mismos", humanos o no-humanos.

Ya Bateson había vislumbrado en el animismo de las "sociedades tradicionales" la expresión de un pensamiento más apto para comprender la estructura conectiva de la que defino como una co(s)munidad, es decir, una sociedad epistémica que se extiende más allá de lo humano. Esto porque el animismo implica ampliar el concepto de mente y personalidad al mundo circunstante, reconociendo otros "si-mismos" no humanos inter-agentes en la construcción de la mente y personalidad del hombre. Es en esta misma perspectiva que, refiriéndose a los runa de la Amazonia ecuatoriana, Kohn (2021) considera el animismo como la necesidad de reconocer e interactuar con seres semióticos que son sí mismos en toda su diversidad. Se trata de una necesidad ontológica basada en el hecho de reconocer que existen otros tipos de seres pensantes más allá de lo humano, los cuales contribuyen a la construcción de una comunidad ecológica; en el caso de los runa de la Amazonia, un bosque pensante. ${ }^{5}$

Sin embargo, es Viveiros de Castro quien, vislumbrando en los mitos fundacionales indígenas un paisaje más vasto, no solo amazónico sino panamericano, teoriza la posibilidad de una ontología alternativa con base antropomórfica, en la cual los demás seres vivientes tienen un punto de vista humano y el mundo un origen antropomorfo.

La proposición presente en los mitos indígenas es: los animales eran humanos y dejaron de serlo, la humanidad es el fondo común de la humanidad y de la animalidad. En nuestra mitología es lo contrario: los humanos éramos animales y "dejamos" de serlo, con la emergencia de la cultura, etc. Para nosotros, la condición genérica es la animalidad: "todo el mundo" es animal, sólo que algunos (seres, especies) son más animales que otros: nosotros los humanos somos evidentemente los menos animales de todos [...] En las mitologías indígenas, muy por el contrario, todo el mundo es humano [...] Todo esto converge con la actitud que se acostumbra llamar "animismo", la presuposición o

\footnotetext{
${ }^{4}$ Recordamos que, como he mencionado anteriormente, la interpretación excede la representación simbólica; en este sentido, todos los seres vivientes, en cuanto constitutivamente semióticos, producen interpretación, encarnan un punto de vista. (Kohn, 2021: 127)

${ }^{5}$ El título de la obra de Kohn (2021) es Cómo piensan los bosques.
} 
intuición pre conceptual (el plano de inmanencia, diría Deleuze) de que el fondo universal de la realidad es el espíritu. (Viveiros de Castro, 2013: 18)

Esta interpretación del animismo, que se extiende también al mundo vegetal y hasta las piedras, es una suerte de modelo general que, como advierte el mismo autor, "[...] se aleja en mayor o menor medida de todas las realidades etnográficas que lo inspiraron" (Viveiros de Castro, 2013: 16). Sin embargo, identifica una diferencia fundamental respecto al naturalismo de la modernidad occidental, poniendo en evidencia una función onto-epistémica central en muchas ecocosmologías tradicionales: el tentativo de entender el punto de vista de otros de sí no-humanos desde una perspectiva subjetiva; animista, antropomorfa, pero no antropocéntrica.

Este tentativo representa una epistemología de signo diferente respecto a la ciencia. En efecto, las ecocosmologías de las comunidades indígenas no se basan en la observación de hechos científicos, según la tradicional separación sujeto/objeto, sino en un con-conocer que requiere de una subjetivación de lo conocido, cuya expresión más paradigmática se encuentra en el chamanismo, es decir, un proceder "[...] por atribución de subjetividad o 'agencia' a las así llamadas cosas" (Viveiros de Castro, 2013: 28). Para ejemplificar este proceso en el contexto mexicano, podríamos pensar a la filosofía implícita de los tojolabales descrita por Lenkersdorf (2005) a partir del análisis de su lengua. Según Lenkersdorf se puede afirmar que, en lugar de objetos, en la lengua tojolabal hay diferentes clases de sujetos que se complementan; lo que hace que se dé una subjetividad-intersubjetiva en lugar de una relación sujeto/objeto. Es decir, que cualquier experiencia humana, y por ende también la cognoscitiva, es constitutivamente intersubjetiva, independientemente de la naturaleza de los otros seres de la relación.

Por otro lado, esta forma otra de conocer "con" la naturaleza implica buscar una comunicación con los otros de sí no-humanos interpretando sus propios "códigos" semióticos. Estos intentos de comunicación trans-especie están documentados, entre otros trabajos (Haraway, 2008), en la investigación de Kohn entre los runa de la Amazonia, los cuales, para alejar a los pericos de sus maizales, construyen espantapájaros, imaginando "[...]cómo se ve un ave rapaz desde la perspectiva del perico" (2021:122). De manera similar, tratan de interpretar los sueños de los perros, de comunicarse con ellos y de educarlos para enseñarles a identificar los depredadores, a no cazar los animales domésticos, pero sí los del bosque. En ambos casos los runa buscan construir un sistema de comunicación trans-especie que contempla la utilización de signos icónicos e indexicales ${ }^{6}$ propios de los sistemas vivos preverbales (2021: 179-209); es decir, propios del mundo de la Creatura más allá de lo humano.

\section{Epistemología y pedagogía subyacente a las ecocosmologías indígenas}

Ahora bien, si interpretamos, desde esta perspectiva, algunos de los núcleos fundamentales de las formulas discursivas que sintetizan el "activismo ambiental" y el "buen vivir" de las ecocosmologías indígenas, como, por ejemplo, "la Tierra es nuestra madre", "el río es hermano", "toda cosa tiene corazón”, puede que dichas afirmaciones no tengan, estrictamente, un valor científico, o, por lo menos, para los enfoques reduccionistas. Sin embargo, desde la perspectiva del silogismo de la metáfora descrito anteriormente con relación a Bateson, estas fórmulas se podrían entender como el intento de reconocer el "pegamento organizacional" del eco-sistema mental, es decir, la interconexión entre las diversas entidades que lo constituyen.

En este sentido, Bateson veía en el animismo de las sociedades tradicionales una manera de concebir el con-conocimiento bajo la forma de la coevolución. Dicho en otras palabras, consideraba que la idea de proyectar al mundo más allá del humano un alma o un espíritu representa el tentativo de entender que ningún ser en la Tierra puede evolucionar solo, sino siempre en relación con otras entidades,

\footnotetext{
${ }^{6}$ Sobre cómo Kohn usa la teoría semiótica de Pierce, véase Kohn (2021: 37-95).
} 
y que este co-evolucionar implica un con-conocer, es decir, un adaptarse mutuamente y adquirir hábitos de manera compartida. Esto implica considerar el conocer como una habilidad no solamente humana, que se expresa a través del lenguaje y el simbolismo, sino de todos los demás sistemas vivos, que se manifiesta en los signos que conforman la adaptación evolutiva, la genética y la embriología. La epistemología, de hecho, para Bateson, es el ámbito en la cual el pensamiento humano converge con aquello de los demás sistemas biológicos. Y dicha convergencia parece emerger con mayor fuerza en los mitos, conocimientos y prácticas de las sociedades animistas, las cuales, según el científico, son más sensibles a los problemas ecológicos, en la medida en que son más conscientes de la interrelación que une todos los sistemas vivos.

Esta "conciencia" influye en los saberes y las prácticas tradicionales indígenas, sobre todo las basadas sobre el aprovechamiento sustentable de los "recursos" naturales, que intentan limitar el inevitable impacto humano sobre la Tierra. Los rituales tradicionales que acompañan dichas prácticas, como, por ejemplos, para pedir permiso y agradecer la "Pachamama", cumplen una función pedagógica importante, trasmitiendo: el valor de un ser-aprender-y-crecer-junto con la naturaleza; la importancia de buscar medios de comunicación trans-especie con los otros sistemas vivientes; el ideal de no profanación del límite ecológico. Estos rituales se basan sobre la consideración de que la Tierra está "encantada" (Gramigna y Rosa, 2016), es decir, tiene agencia, es un ser semiótico que produce pensamientos, aunque no simbólicos. En este sentido, fungen como suerte de recordatorio, para el hombre, de que pensar a través del silogismo de la metáfora ("la Tierra es madre" "el río es hermano", "todo tiene corazón") significa el esfuerzo para "conocer-con" los sistemas biológicos no-verbales y, al mismo tiempo, comprenderse parte de dichos sistemas.

El precepto que define el límite ecológico del actuar humano, contenido en estos rituales, no se dirige al caso particular, es decir, a la desaparición de un agente no-humano específico, planta o animal, debido al inevitable impacto ecológico del hombre, sino al peligro de la pérdida más generalizada del equilibrio, resultante de la pretensión de dominio del hombre sobre la naturaleza. En esta perspectiva, las fórmulas discursivas arriba mencionadas ("el río es hermano", "todo tienen corazón"...) adquieren una profunda relevancia ética y ecológica, resonando como una suerte de advertencia, para la sociedad occidental, de que el aumento exponencial y cualitativo del impacto ecológico es provocado por un error onto-epistémico que yace en el seno del antropocentrismo: la falta de reconocimiento de ser parte de una estructura viviente y epistemológica más amplia, y el abandono a la sola lógica egoísta ${ }^{7}$ de la representación simbólica e instrumental del propósito consciente. Hábitos cognitivos que, en sus extremas consecuencias, amenazan, como vimos, con generar un sentimiento de separación radical del resto de la Creatura. En efecto, es asumiendo a-problemáticamente esta disociación como natural que se realimenta la separación entre cultura (ámbito privilegiado de lo humano) y naturaleza (ámbito del resto de la Creatura), justificando el domino antropocéntrico de la primera sobre la segunda. Mientras los mitos ecocosmológicos, por no desarrollar un concepto de naturaleza (Danowsky y Viveiros de Castro, 2017) y, consecuentemente, de cultura como dimensión separada y superior, desdibujan los límites entre estos dos ámbitos, vislumbrando otra realidad; más propiamente, otra ontología, otra naturaleza y otra sociedad, en la cual la comunidad se extiende más allá de lo humano, dando vida a una co(s)munidad de entidades humanas y no-humanas en interacción.

Lo que llamamos mundo natural, o "mundo" en general, es, para las poblaciones [amerindias], una multiplicidad de multiplicidades intrínsecamente conectadas. Los animales y las otras especies se conciben como tantos tipos de "personas" o "pueblos", es decir, como entidades políticas... Lo que nosotros llamamos medio ambiente es para ellos una sociedad de sociedades, un escenario internacional, una cosmopoliteia. (Danowsky y Viveiros de Castro, 2017: s/p; la traducción es mía)

\footnotetext{
${ }^{7}$ Egoísta en el sentido de que pretende que el significado dependa exclusivamente del hombre por su capacidad de representación simbólica. Ergo: más allá de la representación simbólica no existe significación.
} 
En esta perspectiva, si el antropocentrismo limita la posibilidad de existencia de la sociedad a lo humano, las ecocosmologías indígenas la amplían al resto de la Creatura: todo es sociedad porque todo es cultura; en cuanto todo ser vivo es capaz adquirir hábitos (conocer) y modificar aquellos de otros seres vivientes.

\section{Interculturalidad hombre-naturaleza}

Esta idea de co(s)munidad conlleva, entre muchas otras y profundas implicaciones, la posibilidad de re-pensar la Interculturalidad bajo una nueva luz. Se trata de la ampliación del concepto a la relación y comunicación entre entidades humanas y no-humanas, donde la idea de cultura se extiende más allá de la capacidad simbólica del hombre, para abarcar el más amplio ecosistema de signos y significados que producen todos los demás seres vivientes que conforman la naturaleza. En otras palabras, la idea de co(s)munidad nos abre a la eventualidad de interpretar la relación hombre-naturaleza como una relación intercultural: entre una cultura humana y una cultura no-humana.

Esto, por atrevido que aparezca, no es todo, en cuanto la idea de co(s)munidad nos sugiere algo aún más desafiante. Ampliando el concepto de Interculturalidad para extenderlo a la naturaleza como agente cultural y epistémico, insinúa que la Interculturalidad, como la consideramos tradicionalmente, ya no es adecuada para estudiar las relaciones entre sociedades antropocéntricas y co(s)munitarias, por lo que parece sugerir un deslice hacia lo ontológico, para entenderse como una relación entre ontologías. Esto, por la siguiente razón. Lo que está en juego en la relación entre sociedades antropocéntricas y co(s)munitarias no es la noción de cultura como se concibe desde la ideología multiculturalista, es decir, la idea según la cual existe una única naturaleza universal y una pluralidad de culturas que la interpretan según sus creencias (Viveiros de Castro, 2010), sino la noción misma de mundo, lo cual sugiere la existencia de ontologías y naturalezas diferentes. Por un lado, "un mundo" que considera la naturaleza como "separada" y como "recurso" (antropocentrismo), por el otro, uno que la considera también como un ser, un sujeto, un individuo interrelacional [co(s)munidades].

Lo mencionado implica una complejización del pluralismo, es decir, un tomar conciencia de que al entrar en contacto con sociedades co(s)munitarias, los supuestos de la lógica multiculturalista (la idea de naturaleza, cultura, ser, mundo, etc.) dejan de ser referentes universales, solicitando buscar otras significaciones a la luz del contacto y conflicto entre ontologías diferentes. Se trata de una necesidad pragmática, dado que las disputas medioambientales entre las comunidades indígenas y el Estado, que aquejan a toda la región latinoamericana, surgen del choque entre ontologías. Por un lado, el Estado, que a pesar de los giros constitucionales que reconocen los derechos de la naturaleza, como en Ecuador, sigue considerándola como un mero recursos por explotar en nombre del bienestar y el desarrollo; por el otro, las comunidades originarias, que defienden la tierra en nombre de los hermanos ríos, de los espíritus o de otras entidades que los habitan, poseen y protegen.

En este sentido, el deslice, o "giro" ontológico en el campo de la interculturalidad — que, ciertamente, necesita de un ulterior y más profundo análisis - puede contribuir a la reflexión y estudio de las relaciones entre culturas, ampliando el propio campo de análisis de la interculturalidad a la relación con la naturaleza como un "sujeto" histórico, político y cultural emergente. Por la misma razón, puede tener alcances significativos en el ámbito de la educación ambiental, en cuanto arroja nueva luz sobre la manera de considerar la naturaleza como dotada de agencia pedagógica; es decir, activamente en el marco de las relaciones de enseñanza-aprendizaje. Lo que nos abre a la posibilidad de una pedagogía más allá de lo humano. 


\section{Algunas reflexiones conclusivas (pero preliminares) para pensar en una pedagogía más allá de lo humano}

La pedagogía implícita en la hominización de los androides y de los primates, descrita en las célebres películas de Blade runner (1982) y Rise of the planet of the apes (2011), es demasiado humana. Las consecuencias oscuras de una sociedad hipertecnológica, en el primer caso, y de una "involución" distópica en el segundo, aparecen, de hecho, como efectos del antropocentrismo llevado a sus más extremas consecuencias: hacer del hombre ya no solo la medida, sino la forma y sustancia de todas las cosas.

En contraposición a estas visiones distópicas, la pedagogía más allá de lo humano inspirada por las ecocosmologías indígenas, en diálogo con la ecología de la mente de Bateson, la biosemiótica de Kohn y el perspectivismo de Viveiros de Castro, nace de la necesidad de deconstruir el mito autoevidente de la naturaleza humana establecido con el humanismo ilustrado y el racionalismo moderno — su centralidad en el modelo antropocéntrico- (Braidotti, 2015), para proponer al hombre el papel de co-protagonista y co-constructor en el escenario de la coevolución. En este sentido, consiste en una pedagogía posthumana porque, reconociendo la parcialidad del modelo antropocéntrico frente a otras formas de entender la naturaleza y habitarla, se proyecta más allá de los límites de la subjetividad y sociedad establecidos por la moderna concepción del hombre; sin subestimar, sin embargo, su valor en sentido absoluto. Creo, al contrario, que una pedagogía más allá de lo humano puede vigorizar el papel del hombre, reconociendo en él el privilegio de la responsabilidad hacia el más amplio contexto ecosistémico al cual pertenece y que contribuye a dar vida. $\mathrm{Si}$ " [...]pensar moralmente y actuar éticamente requiere de la referencia simbólica" (Kohn, 2021: 183), entonces, una de las formas en que se expresa dicho privilegio simbólico, exclusivamente humano, es la asunción de la responsabilidad ante los demás sistemas vivos.

Dicha responsabilidad, nos recuerdan Bateson y los mitos ecocosmológicos, solicita, antes que nada, un ejercicio de concientización epistémica: dado que la coevolución, como vimos, implica conconocimiento con otras especies o, más precisamente, con otros sistemas mentales no-humanos, esto significa que una mala epistemología, es decir aquella que no reconoce la interdependencia, conlleva el riesgo de un progreso enfermo que infecta la evolución desequilibrándola (Bateson, 2006); amenazando, como demuestra la crisis ecológica contemporánea, con la destrucción de la biodiversidad y la consecuente propagación de virus letales.

En esta perspectiva, apoyándose en la ecología mental y en la teoría biológica del conocimiento (Maturana y Varela, 2003), una posible pedagogía más allá de lo humano debería asumir el conocimiento, y por lo tanto el aprendizaje, a la luz de la convergencia entre el conocer humano y el conocer del resto de los sistemas biológicos, reconociendo las semejanzas que nos hacen ser "lo mismo" sin ser iguales, y diversos sin ser separados del resto de la Creatura. Deberá reconocer, entonces, que todo ser vivo, en cuanto sistema mental, es una entidad que aprende, pero que también, conditio sine qua non, enseña. Y esto por una razón tan sencilla cuanto evidente: así como ningún acto semiótico se da en el vacío, de igual forma no existe aprendizaje posible sin un contexto relacional. Donde lo que cambia, respecto a la idea "tradicional" de relación educativa, es la definición de contexto, que se complejiza por la extensión de la subjetividad y de la sociedad a todo aquello que, según la visión antropocéntrica, queda ontológicamente excluido de dichas definiciones: animales, plantas, ríos, ecosistemas...virus, etc. En esta perspectiva, una pedagogía más allá de lo humano nace de la necesidad de comprender pedagógicamente el proceso de enseñanza-aprendizaje que surge del con-conocer en los contextos co(s)munitarios, es decir, las sociedades que se construyen en la interrelación con entidades no-humanas.

Esto nos permite formular unas primeras preguntas fundamentales para pensar una pedagogía más allá de lo humano: ¿qué significa enseñar y aprender de otro de sí no-humano? Y ¿cómo se realizaría dicho proceso? 
Estas preguntas interpelan directamente a la pedagogía, como ciencia que se encarga del estudio de la enseñanza-aprendizaje en sus múltiples y variadas manifestaciones. Sin embargo, en esta tarea, le solicitan el esfuerzo de superar el contexto delineado por el estatuto tradicional de su disciplina, la formación del hombre, para proyectarse hacia la comprensión de la formación en el marco de una manera otra de considerar la subjetividad y la sociedad, en una perspectiva co(s)munitaria y cosmo(s)política. En este sentido, lo que se le pide es un esfuerzo que trasciende los límites contemporáneos de su campo epistemológico y teórico, solicitando una reorganización inter y transdisciplinaria e inter y trans-cultural de su saber; lo que rebasa, en mi opinión, también los importantes avances de la contemporánea educación ambiental; así como, por supuesto, la reflexión realizada hasta aquí, que no alcanza para expresar más de lo que pretende.

El trabajo por realizar hacia una pedagogía más allá de lo humano, asumiendo que esta propuesta sea metodológicamente justificada y plausible (sobre esto habría que debatir) y socialmente pertinente (la crisis ecológica y sanitaria contemporánea nos hace pensar en una afirmativa), es sumamente complejo y amplio, no solamente por los límites epistemológicos del saber pedagógico, sino también por las relaciones cotidianas y domésticas que establecemos con los animales, fuertemente centradas en la superioridad del hombre y desbalanceada hacia nuestra comunicación. En este sentido, creo que una pedagogía más allá de lo humano se extiende mucho más allá, aunque no lo excluye totalmente, de la convivencia y el entrenamiento de nuestros animales domésticos.

Al mismo tiempo, creo que una pedagogía de este tipo se proyecta también más allá del "conocimiento de" la naturaleza cimentada en la ciencia, dado que esta, aunque pretende hablar la lengua de la naturaleza, y en muchos casos lo hace de manera sorprendente, se "queda corta", por ser, quizá, el lenguaje más simbólico, abstracto y, por esto, más humano que exista. En este sentido, creo que se podría afirmar, de manera conclusiva pero preliminar, que uno de los principios de esta posible pedagogía más allá de lo humano se encuentra en el concepto de límite, muy cercano a aquel de responsabilidad; dado que no puede haber límite sin responsabilidad y viceversa. Con este propósito, Kohn, escribe:

Dado que [...] el lenguaje humano está anidado dentro de un campo representacional más amplio constituido por procesos semióticos que emergen y circulan en el mundo viviente no humano, proyectar el lenguaje sobre este mundo no humano nos ciega a estas otras modalidades representacionales y a sus características. (Kohn, 2021: 219)

En este sentido, el límite de no proyectar nuestro lenguaje al mundo no-humano hace emerger una primera y posible función de la pedagogía posthumana: silenciar algunas habilidades cognitivas para tratar de explorar otras más aptas para entender la comunicación semiótica de lo que vive más allá de nuestra piel. Creo que dicha función no debería verse como una limitación tout court, sino, al contrario, como una expansión de las habilidades cognitivas del hombre para comprender el mundo de la Creatura desde adentro y en todas sus variadas, multiformes, agradables y desagradables manifestaciones.

Para concluir. Todo esto, quizá, y más allá de la provocación, nos podría llevar a pensar que, si aniquilar virus letales, como el actual, es sin lugar a duda la estrategia más pragmática en el corto y mediano plazo, para la sobrevivencia de la sociedad humana así como la conocemos, puede que no sea una acción suficiente para entender que quiere decirnos y enseñarnos una pandemia como la actual; para entender que algunos hábitos de la ya mítica "vieja" normalidad han sido corresponsables de su desencadenamiento. También por esto, una pedagogía más allá de lo humano sería útil. 


\section{Bibliografía}

BATESON, Gregory (1989), "La metáfora y el mundo del proceso mental”, en Thompson, William Irwin (ed.), Gaia: Implicaciones de una nueva biología. Clark Gaia, Darryl y Carletto Carbó (trads.). Barcelona, Kairos, pp. 37-46.

BATESON, Gregory (2006), Verso un'ecologia della mente. Longo, Giuseppe y Giuseppe Trautteur (trads.). Adelphi, Milano.

BATESON, Gregory (2010), “Intelligenza, esperienza ed evoluzione”, en Donaldson, Rodney (coord.), Una sacra unità. Altri passi verso un'ecologia della mente. Longo, Giuseppe (trad.). Adelphi, Milano, pp. 408-422.

BATESON, Gregory (2011), Espiritu y naturaleza. Leandro Wolfson (trad.). Buenos Aires, Amorrortu.

BATESON, Gregory y Mary Catherine BATESON (2013), El temor de los ángeles. Epistemología de lo sagrado. Bixio, Alberto L. (trad.). Barcelona, Gedisa.

BraidotTi, Rosi (2015), Lo Posthumano. Gentile Vitale, Juan Carlos (trad.). Barcelona, Gedisa.

CORTES, Agathe (2020), "Un estudio calcula que el colapso de los ecosistemas se producirá a partir de 2030 si no se actúa". El país. Consultado en <https://elpais.com/ciencia/2020-04-08/un-estudio-calculaque-el-colapso-de-los-ecosistemas-se-producira-a-partir-de-2030-si-no-se-actua.html> (10/03/2021).

DANOwSKY, Debora y Eduardo ViVEIROS DE CASTRO (2017), Esiste un mondo a venire? Saggio sulle paure della fine. Lucera, Alessandro y Alessandro Palmieri (trads.). Roma, Nottetempo, Edición Kindle.

DE SOUSA SANTOS, Boaventura (2010), Para descolonizar occidente. Más allá del pensamiento abismal. Buenos Aires, CLACSO - Prometeo Libros.

DeAcon, Terrence W. (1997), The symbolic Species. The co-evolution of language and the brain. New York, Norton.

DEACON, Terrence W. (2013), Naturaleza incompleta: cómo la mente emergió de la materia. García Leal, Ambrosio (trad.). Barcelona, Tusquets Editores S. A.

Dennet, Daniel (2000), Tipos de mentes. Hacia una comprensión de la conciencia. Páez de la Cadena, Francisco (trad.). Madrid, Debate.

ENCISO, Angélica (2020), "De continuar el daño al ambiente, otras pandemias volverán a aparecer”, La jornada. Consultado en <https://www.jornada.com.mx/ultimas/sociedad/2020/06/03/de-continuar-eldano-al-ambiente-otras-pandemias-volveran-a-aparecer-147.html> (15/02/2021).

GALANO, Carlos (2005), "Complejidad, diálogo de saberes, nuevo pensamiento y racionalidad ambiental”. En Secretaría de Ecología del Estado de México, Universidad del Estado de México, Congreso Nacional de Educación Ambiental de la Región Centro de la República de México. Toluca, UEAM, CECADESU, SEMARNAT. Consultado en <http://www.biodiversidadla.org/content/view/full/16018> $(15 / 12 / 2021)$.

Gramigna, Anita y Carlo Rosa (2016), Il mondo degli incanti. Un'indagine di campo presso la tribù yaqui del Sonora. Roma, Aracne.

HAmilton, Clive; BONNEuIL, Christophe y François GEMENNE (eds.) (2015), The anthropocene and the global environmental crisis: rethinking modermity in a new epoch. London, Routledge, Taylor \& Francis Group.

Haraway, Donna J. (2008), When species meet. Minneapolis, University of Minnesota Press.

HORNBORG, Alf (2001), "La ecología como semiótica. Esbozo de un paradigma contextualista para la ecología humana”, en Descola, Philippe y Gísli Pálsson (coords.), Naturaleza y Sociedad. Perspectivas antropológicas. Mastrangelo, Stella (trad.). Ciudad de México, Siglo XXI editores, pp. 60-79. 
KoHn, Eduardo, (2021), Cómo piensan los bosques. Cuéllar Gempeler, Mónica y Belén Agustina Sánchez (trads.). Quito-Ecuador, Abya Yala.

Latour, Bruno (2019), Donde aterrizar. Cómo orientarse en política. Cuartas, Pablo (trad.). Barcelona, Taurus.

LeFF, Enrique (2012), "Pensamiento Ambiental Latinoamericano. Patrimonio de un Saber para la Sustentabilidad", en Environmental Ethics, vol. 34, Issue Supplement, pp. 97-112.

LenKersdorf, Carlos (2005), Filosofas en clave tojolabal. Ciudad de México, Porrúa.

MATURANA, Humberto y Francisco VARELA (2003), El árbol del conocimiento: las bases biológicas del entendimiento bumano. Buenos Aires, Lumen.

MORIN, Edgar (1973), Le paradigme perdu: la nature bumaine. Paris, Editions du Seuil.

Noguera de ECHEVERri, Ana Patricia (2004), El reencantamiento del mundo. México-Colombia, Programa de las Naciones Unidas para el Medio Ambiente (PNUMA), Universidad Nacional de Colombia, IDEA.

RAPPAPORT, Roy A. (1971), "Naturaleza, cultura y antropología ecológica”, en Shapiro, Harry L. (ed.), Hombre, cultura y sociedad. Ciudad de México, Fondo de Cultura Económica, pp. 261-292.

RUíz SERENA, Daniel y Carlos DEL CAIRO (2016), "Los debates del giro ontológico en torno al naturalismo moderno", en Revista de Estudios Sociales, vol. 55, pp. 193-204. DOI: $<$ http://dx.doi.org/10.7440/res55.2016.13>.

STENGER, Isabelle (2014), "La propuesta cosmopolítica", en Pléyade. Revista de Humanidades y Ciencias Sociales, vol. 14, pp. 17-41.

STERLING, Stephen (2011), “Towards Anticipative Education - Learning by Design”, en Harding, Stephen (ed.) Grow Small, Think Beautiful. Ideas for a Sustainable World from Schumacher College. Edinburgh, Floris Books.

TOLEDO, Víctor y Narciso BARRERA-BASSOLS (2008), La memoria biocultural. La importancia ecológica de las sabidurías tradicionales. Barcelona, Icaria Editorial.

VIVEIROS DE CASTRO, Eduardo (2013), La mirada del jaguar: introducción al perspectivismo amerindio. Buenos Aires, Tinta Limón. 